\title{
Restoration of ankle movements with the ActiGait implantable drop foot stimulator: a safe and reliable treatment option for permanent central leg palsy
}

\author{
${ }^{*}$ Klaus Daniel Martin, MD, ${ }^{1}$ Witold Henryk Polanski, MD, ${ }^{1}$ Anne-Kathrin Schulz, ${ }^{1}$ \\ Michael Jöbges, MD, ${ }^{3}$ Hansjoerg Hoff, MD, ${ }^{2}$ Gabriele Schackert, PhD, ${ }^{1}$ Thomas Pinzer, MD, ${ }^{1}$ and \\ Stephan B. Sobottka, MD1
}

1Department of Neurological Surgery, Carl-Gustav-Carus University Hospital of the Technical University of Dresden; and
2Radiologische Praxis Dresden, and ${ }^{3}$ Neurologic Rehabilitation Centre, Brandenburg Klinik, Bernau-Waldsiedlung, Germany

OBJECTIVE The ActiGait drop foot stimulator is a promising technique for restoration of lost ankle function by an implantable hybrid stimulation system. It allows ankle dorsiflexion by active peroneal nerve stimulation during the swing phase of gait. In this paper the authors report the outcome of the first prospective study on a large number of patients with stroke-related drop foot.

METHODS Twenty-seven patients who experienced a stroke and with persisting spastic leg paresis received an implantable ActiGait drop foot stimulator for restoration of ankle movement after successful surface test stimulation. After 3 to 5 weeks, the stimulator was activated, and gait speed, gait endurance, and activation time of the system were evaluated and compared with preoperative gait tests. In addition, patient satisfaction was assessed using a questionnaire.

RESULTS Postoperative gait speed significantly improved from 33.9 seconds per 20 meters to 17.9 seconds per 20 meters $(p<0.0001)$, gait endurance from 196 meters in 6 minutes to 401 meters in 6 minutes $(p<0.0001)$, and activation time from 20.5 seconds to 10.6 seconds on average $(p<0.0001)$. In 2 patients with nerve injury, surgical repositioning of the electrode cuff became necessary. One patient showed a delayed wound healing, and in another patient the system had to be removed because of a wound infection. Marked improvement in mobility, social participation, and quality of life was confirmed by $89 \%$ to $96 \%$ of patients.

CONCLUSIONS The ActiGait implantable drop foot stimulator improves gait speed, endurance, and quality of life in patients with stroke-related drop foot. Regarding gait speed, the ActiGait system appears to be advantageous compared with foot orthosis or surface stimulation devices. Randomized trials with more patients and longer observation periods are needed to prove the long-term benefit of this device.

http://thejns.org/doi/abs/10.3171/2014.12.JNS142110

KEY WORDS stroke; drop foot; ActiGait; implantable stimulator; functional neurosurgery

$\mathcal{O}^{2}$ ONTRALATERAL hemiplegia is one of the most frequent causes of disability in stroke patients. ${ }^{11,14} \mathrm{In}$ up to $20 \%$ of stroke patients, a persisting weakness of the contralateral foot is a major cause of gait impairment, usually described as "drop foot." 15 The patients are not able to actively dorsiflex the foot during the swing phase of gait, which results in undesirable compensatory movement patterns, decreased gait velocity, restricted functional mobility, and increased risk of falls., ${ }^{4,9}$

Surface stimulation of the peroneal nerve and an an- kle foot orthosis have been shown to improve the gait of these patients, as well as social participation and quality of life. ${ }^{1,12,17,18}$ Comparing ankle foot orthosis and drop foot surface stimulation, no significant difference in gait speed was found in a randomized single-blind trial. However, user satisfaction was significantly higher in the drop foot stimulation group. ${ }^{12}$

Recently, an implantable 4-channel drop foot stimulator (ActiGait; Neurodan A/S), with independent electrode adjustment resulting in a more specific stimulation, showed

SUBMITTED September 22, 2014. ACCEPTED December 31, 2014.

INCLUDE WHEN CITING Published online July 24, 2015; DOI: 10.3171/2014.12.JNS142110.

DISCLOSURE The authors report no conflict of interest concerning the materials or methods used in this study or the findings specified in this paper.

* Drs. Martin and Polanski contributed equally to this work. 
an improvement of walking speed and a restoration of the physiological ankle movement in patients with stroke-related drop foot. ${ }^{2,3,6}$ The therapeutic effect was found to be improved compared with surface stimulation, combined with an easier handling of the stimulation device. ${ }^{3}$ In this paper we present the first prospective clinical outcome study on a larger number of patients describing the benefit of the ActiGait implantable 4-channel drop foot stimulator for stroke-related drop foot.

\section{Methods}

\section{Patient Characteristics and Screening}

Twenty-seven patients (14 men, 13 women) with a stroke-related spastic hemiparesis, including a drop foot of at least 6-months duration, were treated with the implantable 4-channel drop foot stimulator, ActiGait (for patient characteristics see Table 1). The mean age of the patients was 51.0 years (range 24-66 years). The mean duration of stroke-related drop foot was 63.0 months (range 6-244 months). The drop foot was right-sided in 15 and left-sided in 12 patients. The cause of the central palsy was ischemic in 21 patients and hemorrhagic in 6 patients.

The drop foot was diagnosed according to the criteria of Perry et al. $1995,{ }^{14}$ with a dragging foot during the swing phase. Prior to surgery, the possible benefit of the implantable ActiGait stimulator was tested by external functional surface stimulation of the peroneal nerve (CEFAR Step II, output $60 \mathrm{~mA}$, frequency $20-100 \mathrm{~Hz}$; CefarCompex Scandinavia AB). If a strong dorsiflexion of the ankle could be evoked, the patient was considered to be a candidate for stimulator implantation. In addition, MRI of the leg was performed prior to surgery to exclude any peripheral injury of the peroneal nerve and to determine the anatomical localization of the bifurcation of the sensible branch of the common peroneal nerve for a proper electrode positioning.

\section{Gait Tests and Quality of Life Survey}

To evaluate whether patients with an ActiGait stimulator show changes in walking speed, they were asked to walk 20 meters, and the required time for this action was noted. This test was repeated 3 times without walking aids, with an ankle orthosis, with a surface stimulator preoperatively, and 6 weeks after implantation of the ActiGait system. In each case, the task was repeated with normal and maximal gait speed. Further, patients were asked to walk 6 minutes continuously pre- and postoperatively (walk endurance). The distance covered was measured in meters. Finally, the time needed to stand up from a chair, walk 3 meters, and return to sit down again was measured pre- and postoperatively to determine the needed activation time and to assess the risk of falls (timed up-and-go test). ${ }^{15}$ Furthermore, the patients were asked in a subjective quality of life survey about their satisfaction with the implanted device (Fig. 1). All tests were performed by a neurosurgeon (K.D.M.).

\section{ActiGait Drop Foot Stimulation System}

The ActiGait stimulation system consists of an implantable 4-channel nerve stimulator with a 12-contact electrode cuff, an external control unit, and a heel switch (Fig. 2). The heel switch is worn in a sock and triggers the initiation and termination of each stimulation sequence by a radiofrequency wireless signal to the external control unit when the foot is lifted from the ground. The external control unit is fixed to a belt and can be linked to a personal computer by the physician to set up the individual stimulation parameters. The external control unit enables powering and controlling of the implanted nerve stimulator by an externally wired antenna positioned on the skin over the subcutaneously implanted nerve stimulator body. The nerve stimulator contains a receiver for power and control, and transmits the stimulation to the 12-electrode cuff through a subcutaneous wire.

\section{Surgical Procedure}

Surgery was performed under general anesthesia as previously described by Burridge et al. $^{2}$ In brief, the common peroneal nerve was exposed above the knee for 4 $\mathrm{cm}$ using a longitudinal incision along the tendon of the biceps femoris muscle. For the implantation of the stimulator body, another curved incision at the anterolateral aspect of the upper leg was performed. Ankle dorsiflexion was tested using a nerve stimulator (GN 015; maximum $6 \mathrm{~V}, 10 \mathrm{~mA}, 2.5 \mathrm{~Hz}$; Aesculap). Afterward, the electrode cuff was closed around the nerve and the stimulator body was fixed to the lateral femoral fascia. Before the closure of the incisions, the correct position of the cuff and the stimulator was controlled visually in maximal flexion and extension of the knee, ensuring a free gliding of the cuff.

\section{Postoperative Care and Programming of the Stimulator}

During the first 3 to 5 weeks, the patients had to restrict the movement of his or her operated leg to a maximal knee flexion of $30^{\circ}$. During this period the Achilles tendon was passively stretched to avoid contractures. Afterward, the programming of the system was started. Programming parameters were frequency, stimulation intensity, ramping, and timing of the stimulation channels. Every channel was tested for the best dorsiflexion and the stimulator was activated with $1 \mathrm{~mA}, 20-30 \mathrm{~Hz}$, and an optimal impulse duration of $70 \mu \mathrm{sec}$ (Table 1). Patients were able to readjust the impulse intensity with a patient programmer. Finally, gait evaluation was performed after 4 weeks, measuring gait speed, walk endurance, and the timed up-and-go test. In addition, the subjective quality of life survey was administered.

\section{Statistical Analysis}

The values of the gait tests are expressed as means \pm standard deviations. The significance level was calculated with a Wilcoxon rank-sum test using SPSS software (version 22 , IBM). A p value $<0.05$ was considered statistically significant.

\section{Results}

\section{Surgery and Postoperative Care}

The implantation of the ActiGait system in all patients was easy and without any technical complications. Post- 
TABLE 1. Patient characteristics and individual stimulation parameters with the implantable ActiGait drop foot stimulator

\begin{tabular}{|c|c|c|c|c|c|}
\hline $\begin{array}{l}\text { Case } \\
\text { No. }\end{array}$ & $\begin{array}{l}\text { Age (yrs), } \\
\quad \text { Sex }\end{array}$ & $\begin{array}{l}\text { Side w/ } \\
\text { Drop Foot }\end{array}$ & $\begin{array}{l}\text { Cause of } \\
\text { Drop Foot }\end{array}$ & $\begin{array}{l}\text { Duration of } \\
\text { Drop Foot } \\
\text { (mos) }\end{array}$ & Parameters of Stimulation \\
\hline 1 & $53, M$ & $\mathrm{Lt}$ & Ischemic & 52 & Channel 1 active; $1 \mathrm{~mA} ; 30 \mathrm{~Hz}$; optimal impulse duration $330 \mu \mathrm{sec}$; heel switch ipsilat \\
\hline 2 & $62, \mathrm{M}$ & Rt & Ischemic & 221 & Channel 4 active; 1 mA; $30 \mathrm{~Hz}$; optimal impulse duration 180 sec; heel switch ipsilat \\
\hline 3 & $29, \mathrm{~F}$ & Lt & Ischemic & 48 & Channel $1+4$ active; $1 \mathrm{~mA} ; 35 \mathrm{~Hz}$; optimal impulse duration $60 / 70$ sec; heel switch ipsilat \\
\hline 4 & $58, \mathrm{M}$ & Lt & Ischemic & 16 & Channel 1 active; $1 \mathrm{~mA} ; 30 \mathrm{~Hz}$; optimal impulse duration $90 \mu \mathrm{sec}$; heel switch ipsilat \\
\hline 5 & $25, M$ & Rt & Hemorrhagic & 80 & Channel $1+4$ active; $1 \mathrm{~mA} ; 30 \mathrm{~Hz}$; optimal impulse duration $80 / 50 \mu \mathrm{sec}$; heel switch ipsilat \\
\hline 6 & $59, \mathrm{M}$ & Rt & Ischemic & 23 & Channel 1 active; $1 \mathrm{~mA} ; 30 \mathrm{~Hz}$; optimal impulse duration $80 \mu \mathrm{sec}$; heel switch ipsilat \\
\hline 7 & $64, \mathrm{~F}$ & Rt & Ischemic & 11 & $\begin{array}{l}\text { Channel } 1+4 \text { active; } 1 \mathrm{~mA} ; 30 \mathrm{~Hz} \text {; optimal impulse duration 100/75 } \mu \mathrm{sec} \text {; heel switch } \\
\text { ipsilat }\end{array}$ \\
\hline 8 & $36, \mathrm{~F}$ & Lt & Hemorrhagic & 54 & Channel 4 active; $1 \mathrm{~mA} ; 30 \mathrm{~Hz}$; optimal impulse duration $80 \mu \mathrm{sec}$; heel switch ipsilat \\
\hline 9 & $57, \mathrm{~F}$ & Rt & Ischemic & 27 & Channel 4 active; $1 \mathrm{~mA} ; 30 \mathrm{~Hz}$; optimal impulse duration $90 \mu \mathrm{sec}$; heel switch ipsilat \\
\hline 10 & $36, \mathrm{~F}$ & Lt & Ischemic & 47 & $\begin{array}{l}\text { Channel 1active; } 1 \mathrm{~mA} ; 30 \mathrm{~Hz} \text {; optimal impulse duration } 330 \mu \mathrm{sec} \text {; heel switch (patient is } \\
\text { only in the exercise-mode) }\end{array}$ \\
\hline 11 & $24, \mathrm{~F}$ & $\mathrm{Rt}$ & Ischemic & 55 & $\begin{array}{l}\text { Channel } 1+3+4 \text { active; } 1 \mathrm{~mA} ; 30 \mathrm{~Hz} \text {; optimal impulse duration } 85 / 65 / 45 \mu \mathrm{sec} \text {; heel switch } \\
\text { ipsilat }\end{array}$ \\
\hline 12 & $52, \mathrm{~F}$ & Rt & Ischemic & 71 & Channel 1 active; 1 mA; 20 Hz; optimal impulse duration 150 sec; heel switch ipsilat \\
\hline 13 & $58, \mathrm{M}$ & Rt & Ischemic & 19 & $\begin{array}{l}\text { Channel } 1+4 \text { active; } 1 \mathrm{~mA} ; 30 \mathrm{~Hz} \text {; optimal impulse duration } 110 / 60 \mu \mathrm{sec} \text {; heel switch } \\
\text { contralat }\end{array}$ \\
\hline 14 & $49, \mathrm{~F}$ & Lt & Ischemic & 244 & Channel 4 active; $1 \mathrm{~mA} ; 35 \mathrm{~Hz}$; optimal impulse duration 200 usec; heel switch contralat \\
\hline 15 & $54, \mathrm{M}$ & Lt & Hemorrhagic & 6 & Channel 4 active; 1 mA; 20 Hz; optimal impulse duration 150 sec; heel switch ipsilat \\
\hline 16 & $66, \mathrm{~F}$ & Lt & Ischemic & 90 & Channel $1+4$ active; $1 \mathrm{~mA} ; 20 \mathrm{~Hz}$; optimal impulse duration 110/90 $\mu \mathrm{sec}$; heel switch ipsilat \\
\hline 17 & $54, \mathrm{~F}$ & $\mathrm{Lt}$ & Ischemic & 138 & Channel 4 active; 1 mA; $20 \mathrm{~Hz}$; optimal impulse duration 120 sec; heel switch contralat \\
\hline 18 & $64, \mathrm{~F}$ & $\mathrm{Lt}$ & Ischemic & 17 & Channel 1+4 active; $1 \mathrm{~mA} ; 20 \mathrm{~Hz}$; optimal impulse duration $105 \mu \mathrm{sec}$; heel switch ipsilat \\
\hline 19 & $43, \mathrm{~F}$ & Rt & Hemorrhagic & 60 & $\begin{array}{l}\text { Channel 1+3+4 active; } 1 \mathrm{~mA} ; 20 \mathrm{~Hz} \text {; optimal impulse duration 160/150 } \mu \mathrm{sec} \text {; heel switch } \\
\text { ipsilat }\end{array}$ \\
\hline 20 & $50, \mathrm{M}$ & Rt & Hemorrhagic & 55 & Channel 1 active; $1 \mathrm{~mA} ; 30 \mathrm{~Hz}$; optimal impulse duration $60 \mu \mathrm{sec}$; heel switch ipsilat \\
\hline 21 & $59, \mathrm{M}$ & Rt & Ischemic & 37 & $\begin{array}{l}\text { Channel } 1+2+3 \text { active; } 1 \mathrm{~mA} ; 20 \mathrm{~Hz} \text {; optimal impulse duration 60/70/65 } \mu \mathrm{sec} \text {; heel switch } \\
\text { contralat }\end{array}$ \\
\hline 22 & $54, \mathrm{M}$ & Lt & Ischemic & 70 & Channel 3 active; 1 mA; $25 \mathrm{~Hz}$; optimal impulse duration 145 ㅆec; heel switch ipsilat \\
\hline 23 & $55, \mathrm{M}$ & Lt & Ischemic & 20 & Channel 4 active; $1 \mathrm{~mA} ; 30 \mathrm{~Hz}$; optimal impulse duration $110 \mu \mathrm{sec}$; heel switch contralat \\
\hline 24 & $54, \mathrm{~F}$ & Rt & Ischemic & 97 & Channel 3 active; $1 \mathrm{~mA} ; 30 \mathrm{~Hz}$; optimal impulse duration $100 \mu \mathrm{sec}$; heel switch ipsilat \\
\hline 25 & $48, M$ & Rt & Ischemic & 25 & $\begin{array}{l}\text { Channel } 1+4 \text { active; } 1 \mathrm{~mA} ; 30 \mathrm{~Hz} \text {; optimal impulse duration } 125 / 95 \mu \mathrm{sec} \text {; heel switch } \\
\text { ipsilat }\end{array}$ \\
\hline 26 & $60, \mathrm{M}$ & Rt & Hemorrhagic & 54 & Channel 1 active; 1 mA; 25 Hz; optimal impulse duration 150 sec; heel switch ipsilat \\
\hline 27 & $55, M$ & Rt & Ischemic & 63 & Channel 1 active; 1 mA; 20 Hz; optimal impulse duration 130 usec; heel switch ipsilat \\
\hline
\end{tabular}

operatively, the implantable device did not appear bulky, but was palpable in all patients. Patients 1 and 10 suffered from a nerve injury but recovered completely after 18 months. In both patients, a reoperation was completed. In patient 1 , no organic correlation was found, whereas in patient 10 the nerve injury appeared to be due to a nerve pull by the cuff electrode, which was corrected intraoperatively. In patient 8, a wound healing disorder was found that was then treated locally with a wound examination; no further complications were found. Patient 27 suffered from neurodermatitis and developed an infection of the implant, which ultimately had to be removed. Bleeding was not observed, although 21 patients with an ischemic stroke were treated with acetylsalicylic acid $100 \mathrm{mg}$ per day continuously.

In all patients, the programming of the ActiGait stimu- lator was uncomplicated, as described above. Usually, channel 1 and/or 4 were activated to recruit the motor fibers located anteriorly in the nerve bundle. The handling of the ActiGait system was described by all patients as being uncomplicated and easy in daily living. There were no technical defects of the implanted components. However, in $80 \%$ of the patients, the external heel switch had to be replaced because of a defect. Depending on the activity level in their daily life, the patients had to charge the ActiGait stimulator every 3 to 7 days for approximately 1 hour.

\section{Walking Speed (20-m Gait Test)}

The mean required time for 20 meters of walking with normal walking speed and without any walking aids was $33.9 \pm 11.2$ seconds. After implantation of the ActiGait 


\section{Have you noticed changes in interpersonal contacts and social participation?}
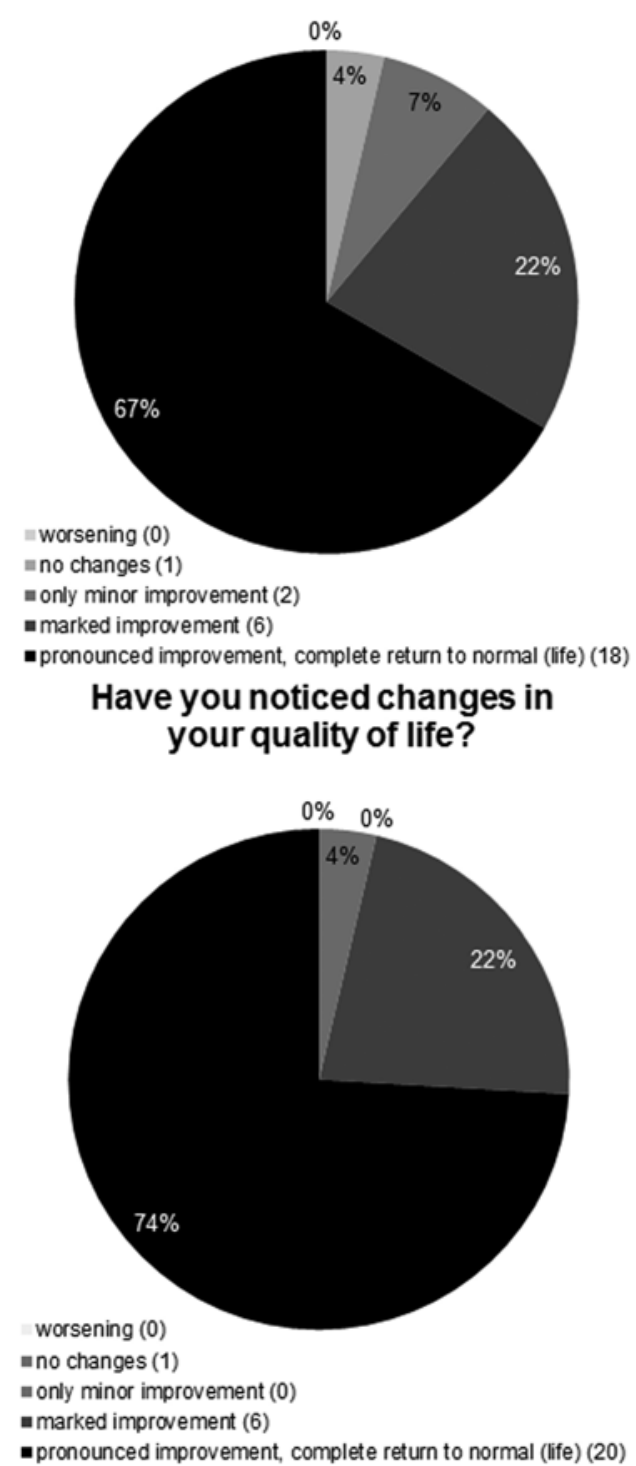

\section{Have you noticed changes in your quality of life?}

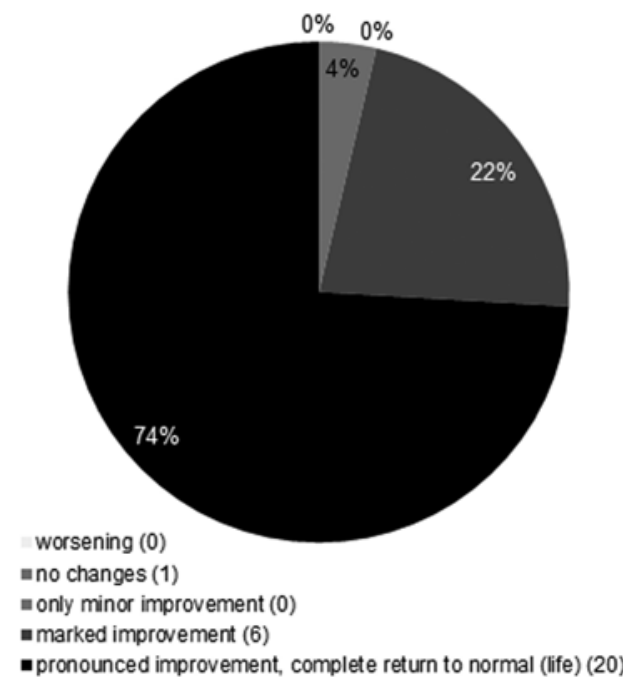

Have you noticed changes in mobility in daily living? (go for a walk, shopping, public

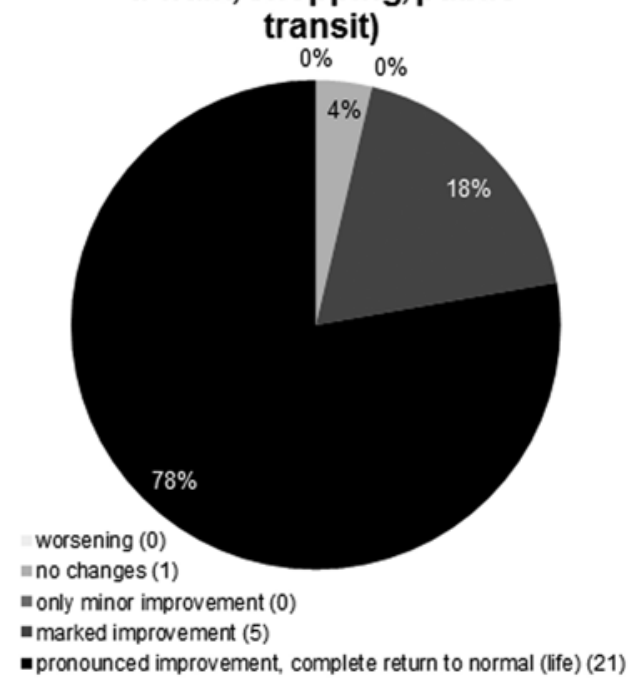

FIG. 1. Quality of life and patient satisfaction survey of the patients who received the ActiGait drop foot stimulator.

stimulator, the required time decreased significantly to $17.9 \pm 5.1$ seconds $(\mathrm{p}<0.0001)$. The surface stimulation also revealed a highly significant $(\mathrm{p}=0.0001)$ reduction of the mean required time to $26.3 \pm 8.2$ seconds, but this result still differed significantly from the results with ActiGait stimulation ( $\mathrm{p}<0.0001)$. The use of an ankle orthosis revealed no significant changes in walking speed compared with no walking aids. Similar results were observed under maximal gait speed conditions (for further details, see Fig. 3A and Video 1).

VIDEO 1. Clip showing the pleasant walking speed test in a patient without walking aids (left) and after implantation of the ActiGait nerve stimulator (right). Copyright Klaus Daniel Martin. Published with permission. Click here to view with Media Player. Click here to view with Quicktime.

\section{Six-Minute Walking Test}

Gait endurance was registered by measuring the covered distance of patients once they had been walking for 6 minutes. Without any walking aids, patients covered on average $196 \pm 40$ meters in 6 minutes. With ActiGait stimulation, the mean distance increased significantly $(\mathrm{p}<$ 0.0001) up to $401 \pm 32$ meters (Fig. 3B).

\section{Timed Up-and-Go Test}

To compare the activation time and the risk of falls in patients without any walking aids and with the implanted ActiGait stimulator, the timed up-and-go test was performed. Without walking aids, the needed time was $20.5 \pm$ 5.3 seconds, which means a functionally relevant mobility 


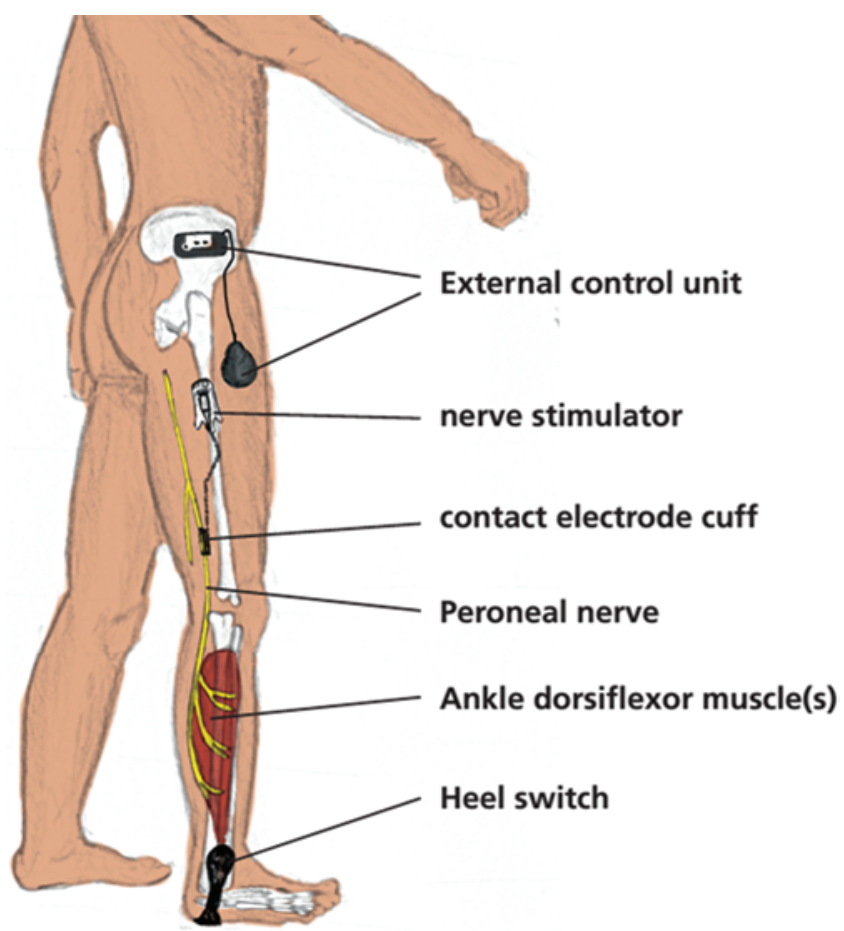

FIG. 2. Illustration of the ActiGait drop foot stimulation system. The hybrid system consists of an implanted nerve stimulator connected to the 12-electrode cuff around the peroneal nerve and an external control unit that contains the power supply, which is triggered by the external heel switch. Copyright Klaus Daniel Martin. Published with permission. Figure is available in color online only. impairment ( $>20$ seconds needed). With ActiGait stimulation, the time was reduced significantly $(\mathrm{p}<0.0001)$ to $10.6 \pm 2.7$ seconds, which can be described as mild mobility impairment (11-19 seconds needed; Fig. 3C).

\section{Subjective Quality of Life and Patient Satisfaction Survey}

For subjective changes in daily living after the implantation of the ActiGait stimulator, patients were asked to answer a short quality of life survey (Fig. 1). Twenty-one patients (78\%) noticed a complete return to normal mobility and 5 patients (18\%) stated a pronounced improvement of mobility. Only 1 patient (4\%) observed no changes. Social participation improved for 2 patients (7\%) marginally, 6 patients $(22 \%)$ reported a marked improvement, and 18 patients $(67 \%)$ noticed a complete return to normal. One patient $(4 \%)$ reported no changes in social participation. The quality of life improved markedly for 6 patients (22\%) and returned to completely normal for 20 patients (74\%). One patient noticed no differences in quality of life. Twenty-three patients (85\%) stated they would recommend the operation, while 3 patients (11\%) were unsure and 1 patient $(4 \%)$ would advise against implantation. This patient, who also reported no changes in quality of life, mobility, and social participation, suffered from the nerve injury mentioned above.

\section{Discussion}

For stroke-related drop foot, ankle foot orthosis and surface stimulator systems are common treatment options. However, ankle foot orthosis may promote development of contracture due to reduced ankle mobility and may appear uncomfortable. ${ }^{5,10,13}$ In contrast, chronic use of
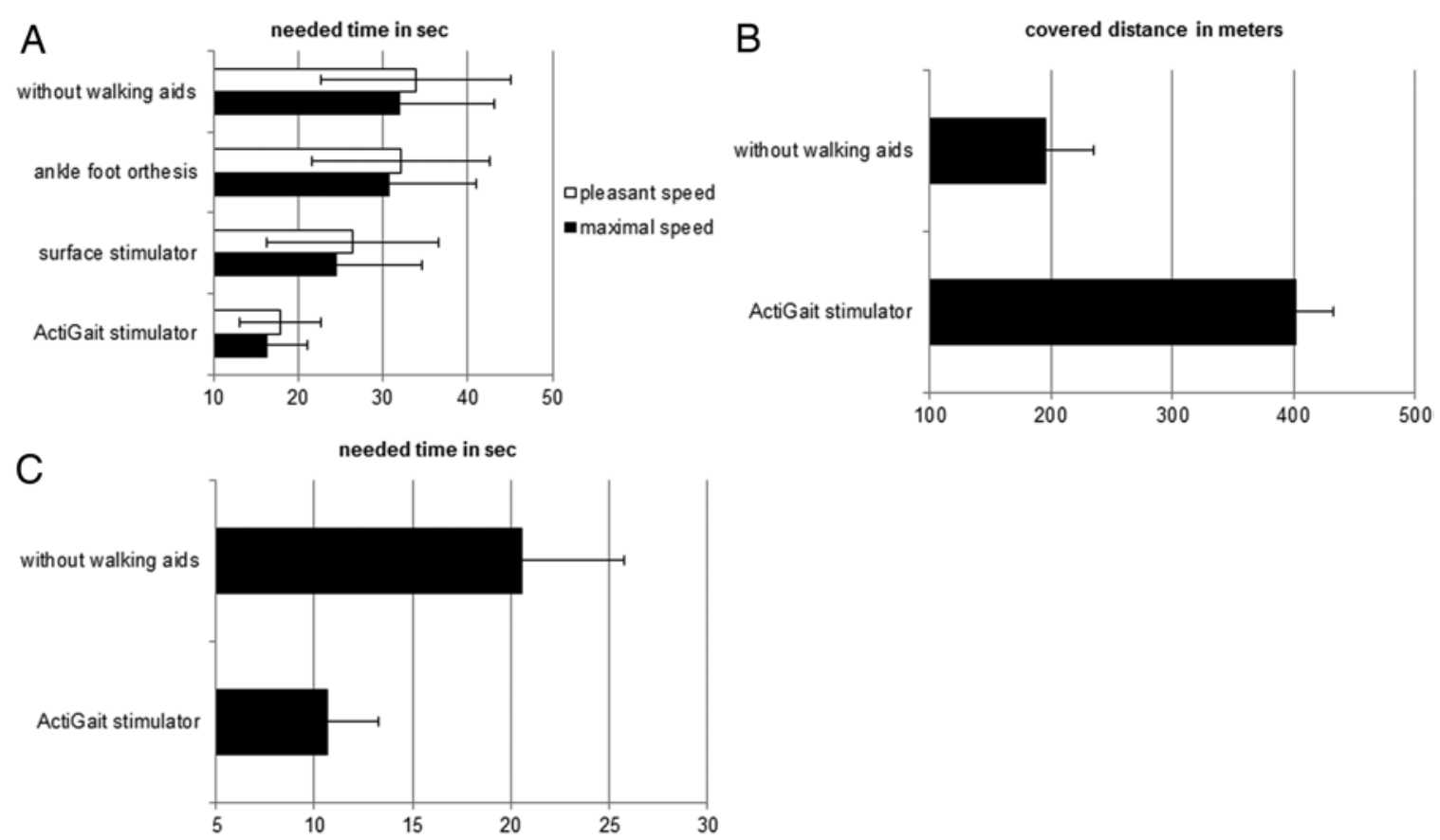

FIG. 3. Results from the pre- and postoperative gait tests of the patients who received the ActiGait drop foot stimulator. A: Maximal and pleasant walking speed without walking aids, with ankle foot orthesis, and with a surface stimulator (all preoperatively) compared with postoperative walking speed with the ActiGait system. B: Pre- and postoperative walking endurance measured by the distance that was covered within 6 minutes. C: Pre- and postoperative timed up-and-go test. 
the surface stimulator appears to strengthen the activation of the motor cortex and their descending connections after long-term use, which may improve gait even when the stimulator is off. ${ }^{7}$ However, electrode positioning in hemiplegic patients is difficult and skin irritations may occur. Therefore, semi-implantable devices were considered. No therapeutic effect was found in a randomized controlled trial using a peroneal nerve stimulator with an external transmitter, a foot switch, and an implantable passive dualchannel stimulator. ${ }^{13}$

In this study, we present the first prospective clinical outcome study on 27 patients with an implantable 4-channel drop foot stimulator (ActiGait) for stroke-related drop foot. Its efficacy and superiority compared with surface stimulation was already reported in another study, including a few patients who suffered a stroke. ${ }^{18}$ Previous to this study, complications have only rarely been reported, such as hematomas at the side of the cuff placement, postoperative lymphedema at the stimulator body (both occurred in 1 of 5 patients), ${ }^{18}$ wound healing deficit (1 of 15 patients), and infections ( 2 of 15 patients), ${ }^{2}$ but injury to the peroneal nerve may also occur. To avoid possible nerve injury, it is important to place the cuff without any nerve tension. The surgery and postoperative care were easy and uncomplicated. Patients had no problems using the ActiGait stimulator in daily living. Additionally, recent reports show that the implantable device was easier to use than the surface stimulator. ${ }^{3}$

We showed in this study that walking speed could be increased significantly (47.2\%) using the ActiGait system. This result is comparable with recent findings, in which ActiGait stimulation revealed an improvement of $19 \%^{2}$ and $25 \%{ }^{18}$ in a 10 -meter gait test. In our study, the implantable stimulation was significantly superior to an ankle foot orthosis and to surface stimulation. This may be explained by the fact that an implantable stimulator produces a considerable orthotic effect with more physiological kinematics in the lower limb. ${ }^{18}$ Furthermore, the electrodes of an implantable system directly surround the peroneal nerve and allow a more specific stimulation with finer adjustability of the stimulation parameters compared with surface stimulation. Patients' gait endurance was also improved significantly by $51.2 \%$. In the timed up-and-go test, which is a standard test to assess risk of falls, a highly significant improvement $(48.2 \%)$ of the needed time was measured for ActiGait stimulation due to a safe gait. In this test, a normal gait without increased risk of falls is determined by a needed time of less than 10 seconds. ${ }^{16}$ With ActiGait stimulation, patients were able to pass the test in a median of 10.6 seconds, which means they had a mild mobility impairment (11-19 seconds needed). Finally, 96\% of our patients noticed an improvement of mobility in daily living, in quality of life, and in social participation. Only 1 patient expressed regrets about the implantable stimulator. Although the presented results of our study are promising, they are limited by a lack of a randomized trial, by the few number of observed patients, and by short evaluation time of 6 weeks postoperatively. Further studies are needed to prove the long-term benefit of the patients regarding the daily usability, long-term satisfaction, quality of life, and functionality and durability of the device.

\section{Conclusions}

The ActiGait system is an advantageous treatment option for patients suffering from a drop foot caused by a permanent cerebral lesion, including insults or hemorrhages.

\section{Acknowledgment}

We thank Andrei Patriciu for the excellent technical help during the surgical procedures and programming of the ActiGait stimulator.

\section{References}

1. Barrett C, Taylor P: The effects of the Odstock drop foot stimulator on perceived quality of life for people with stroke and multiple sclerosis. Neuromodulation 13:58-64, 2010

2. Burridge JH, Haugland M, Larsen B, Pickering RM, Svaneborg N, Iversen HK, et al: Phase II trial to evaluate the ActiGait implanted drop-foot stimulator in established hemiplegia. J Rehabil Med 39:212-218, 2007

3. Burridge JH, Haugland M, Larsen B, Svaneborg N, Iversen HK, Christensen PB, et al: Patients' perceptions of the benefits and problems of using the ActiGait implanted drop-foot stimulator. J Rehabil Med 40:873-875, 2008

4. Cheng PT, Chen CL, Wang CM, Hong WH: Leg muscle activation patterns of sit-to-stand movement in stroke patients. Am J Phys Med Rehabil 83:10-16, 2004

5. Doğan A, Mengüllüoğlu M, Özgirgin N: Evaluation of the effect of ankle-foot orthosis use on balance and mobility in hemiparetic stroke patients. Disabil Rehabil 33:1433-1439, 2011

6. Ernst J, Grundey J, Hewitt M, von Lewinski F, Kaus J, Schmalz T, et al: Towards physiological ankle movements with the ActiGait implantable drop foot stimulator in chronic stroke. Restor Neurol Neurosci 31:557-569, 2013

7. Everaert DG, Thompson AK, Chong SL, Stein RB: Does functional electrical stimulation for foot drop strengthen corticospinal connections? Neurorehabil Neural Repair 24:168-177, 2010

8. Fatone S, Gard SA, Malas BS: Effect of ankle-foot orthosis alignment and foot-plate length on the gait of adults with poststroke hemiplegia. Arch Phys Med Rehabil 90:810-818, 2009

9. Franceschini M, Massucci M, Ferrari L, Agosti M, Paroli C: Effects of an ankle-foot orthosis on spatiotemporal parameters and energy cost of hemiparetic gait. Clin Rehabil 17:368-372, 2003

10. Given JD, Dewald JP, Rymer WZ: Joint dependent passive stiffness in paretic and contralateral limbs of spastic patients with hemiparetic stroke. J Neurol Neurosurg Psychiatry 59:271-279, 1995

11. Hyndman D, Ashburn A: People with stroke living in the community: Attention deficits, balance, ADL ability and falls. Disabil Rehabil 25:817-822, 2003

12. Kluding PM, Dunning K, O’Dell MW, Wu SS, Ginosian J, Feld J, et al: Foot drop stimulation versus ankle foot orthosis after stroke: 30-week outcomes. Stroke 44:1660-1669, 2013

13. Kottink AI, Hermens HJ, Nene AV, Tenniglo MJ, van der Aa HE, Buschman HP, et al: A randomized controlled trial of an implantable 2-channel peroneal nerve stimulator on walking speed and activity in poststroke hemiplegia. Arch Phys Med Rehabil 88:971-978, 2007

14. Lawrence ES, Coshall C, Dundas R, Stewart J, Rudd AG, Howard R, et al: Estimates of the prevalence of acute stroke impairments and disability in a multiethnic population. Stroke 32:1279-1284, 2001

15. Lyons GM, Sinkjaer T, Burridge JH, Wilcox DJ: A review of portable FES-based neural orthoses for the correction of drop 
foot. IEEE Trans Neural Syst Rehabil Eng 10:260-279, 2002

16. Podsiadlo D, Richardson S: The timed "Up \& Go": a test of basic functional mobility for frail elderly persons. J Am Geriatr Soc 39:142-148, 1991

17. Robbins SM, Houghton PE, Woodbury MG, Brown JL: The therapeutic effect of functional and transcutaneous electric stimulation on improving gait speed in stroke patients: a meta-analysis. Arch Phys Med Rehabil 87:853-859, 2006

18. Stein RB, Everaert DG, Thompson AK, Chong SL, Whittaker M, Robertson J, et al: Long-term therapeutic and orthotic effects of a foot drop stimulator on walking performance in progressive and nonprogressive neurological disorders. Neurorehabil Neural Repair 24:152-167, 2010

\section{Author Contributions}

Conception and design: Martin. Acquisition of data: Martin, Polanski, Schulz, Hoff. Analysis and interpretation of data: Polanski, Schulz, Jöbges, Hoff, Sobottka. Drafting the article:
Polanski, Sobottka. Critically revising the article: Polanski, Jöbges, Schackert, Pinzer, Sobottka. Reviewed submitted version of manuscript: Polanski. Statistical analysis: Polanski, Pinzer. Administrative/technical/material support: Polanski, Schackert. Study supervision: Sobottka.

\section{Supplemental Information}

Videos

Video 1, Media Player. http://mfile.akamai.com/21490/wmv/ digitalwbc.download.akamai.com/21492/wm.digitalsource-naregional/jns14-2110_video_1.asx.

\section{Correspondence}

Klaus Daniel Martin, Department of Neurological Surgery, CarlGustav-Carus University Hospital of the Technical University of Dresden, Fetscherstr. 74, 01307 Dresden, Germany. email: daniel. martin@uniklinikum-dresden.de. 